\title{
Recursos públicos para a educação: percentual irrevogável do PIB
}

\section{Resources for public education: irrevocable percentage of GDP}

\author{
Los recursos públicos para la educación: porcentaje irrevocable del PIB
}

\section{João A.C. de Monlevade ${ }^{1}$}

\section{Resumo:}

Este artigo intenciona apresentar uma leitura acerca da execução dos dispositivos da Lei $n^{\circ} 13.005$, de 25 de junho de 2014, que instituiu o novo Plano Nacional de Educação, em particular daqueles contidos na Meta 20, que trata do financiamento da educação brasileira. O texto apresenta e discute a evolução dos percentuais investidos em educação no Brasil, e analisa a proposição de vinculação deste investimento ao Produto Interno Bruto (PIB) do país. Ao final, o artigo conclui analisando o contexto e as dificuldades para a implementação do projeto de financiamento da educação contido no PNE.

Palavras-chave: Financiamento da educação; PIB; PNE.

\begin{abstract}
:
This article intends to present a reading on the implementation of Law No. 13,005, of 25th june 2014, which established the new National Education Plan, in particular about the contained in goal 20, which deals with the financing of Brazilian education. The paper presents and discusses the evolution of the percentage invested in education in Brazil, and analyzes the linking proposition of this investment to gross domestic product (GDP). Finally, the article concludes by looking at the context and the difficulties in implementing the education financing project contained in the PNE.
\end{abstract}

Keywords: Education financing; GDP; PNE.

\section{Resumen:}

Este artículo tiene la intención de presentar una lectura sobre la aplicación de las disposiciones de la Ley № 13.005, de 25 de junho de 2014, que estableció el nuevo Plan Nacional de Educación, en particular las contenidas en el Objetivo 20, que se ocupa de la financiación de la educación brasileña. El artículo presenta y discute la evolución del porcentaje invertido en educación en Brasil, y analiza la propuesta vinculante de esta inversión y el producto interior bruto (PIB). Por último, el artículo concluye observando el contexto y las dificultades en la aplicación del proyecto de financiamiento de educación contenida en el PNE.

Palabras-clave: Financiamiento de la Educación; PIB; PNE. 


\section{Introdução: Uma Metodologia para o Aperfeiçoamento do Plano}

O que pretendo com este artigo, fruto de muito diálogo e de longa reflexão sobre textos legais e propostas legislativas, é, antes de tudo, uma contribuição para a leitura e execução dos dispositivos da Lei $n^{\circ}$ 13.005, de 25 de junhol de 2014, que institui o Plano Nacional de Educação - PNE. Especialmente dos que se resumem na Meta 20 e em suas doze estratégias, sobre o financiamento das ações em educação escolar - básica e superior.

Como foi festejado durante os dolorosos quarenta meses de tramitação, reduziram-se as quase trezentas metas do PNE de 2001-2010 para as vinte do PNE agora em vigor. Entretanto, multiplicaram-se demais as estratégias, quase sempre sem sujeito definido para transformá-las em ações: chegaram a 254, sem considerar os dispositivos inscritos nos 14 artigos introdutórios, tanto ou mais importantes que elas. A verdadeira questão, porém, não estão nesses números. Para se atingir os objetivos do plano, é necessário que as metas, além de claras, contenham marcos graduais em seus indicadores quantitativos e que, acima de tudo, estejam "amarradas" por estratégias de responsabilidade definida entre os atores da República Federativa.

Por exemplo, na meta de atendimento a $50 \%$ da demanda potencial por creches e, sabendo-se que as matrículas em 2013 não atingiam a 25\% da população de zero a três anos de idade, impõe-se saber como deveremos estar no quinto ano de vigência do Plano - inclusive quanto ao percentual a ser atendido por instituições privadas com e sem fins lucrativos - e quais responsabilidades administrativas e financeiras serão assumidas por estratégias da União, dos estados e dos municípios. Na realidade, neste e em outros exemplos, de nada adiantaria a meta ser de 50\%, 70\% ou mesmo 100\% (como ocorre em relação às pré-escolas, tornadas obrigatórias pela Emenda Constitucional n 59, de 2009), se não ficarem claros os encargos federativos nas estratégias. Não ficaram, assim resta a esperança de os Planos Estaduais (PEE) e Municipais (PME) suprirem esta lacuna. No caso do financiamento da educação, não é diferente.

\section{Financiamento da Educação Pública: Evolução dos Percentuais Vinculados}

Segundo o art. 212 da Constituição, duas são as principais fontes de financiamento da educação básica e superior pública, que se responsabiliza hoje por perto de 50 milhões de matrículas: as receitas de impostos vinculados à manutenção e desenvolvimento do ensino (MDE) e a contribuição social chamada Salário Educação.

Desde a Independência, a oferta de escola gratuita foi viabilizada pelo uso de receita de tributos. De 1834 em diante, quando o encargo das escolas primárias e secundárias passou para as províncias, coube a estas investir crescentes verbas - da receita de seus tributos - na educação escolar. Por isso, tanto mais escolas tinha a província que arrecadava mais impostos e deles investia maior percentual em educação.

Com a crescente urbanização do país, ficou escancarada a desproporção entre a demanda por matrículas e a frágil oferta de recursos. A cada ano, no âmbito da União, de cada estado e de cada município, travava-se a disputa por um orçamento maior para as escolas públicas. Daí a luta, já no século XX, no período republicano, pela adoção, em lei, de um percentual de impostos para a Manuntenção e Desenvolvimento do Ensino - MDE. Do Manifesto dos Pioneiros para o texto da Constituição de 1934 - que pretendia democratizar o regime revolucionário de Getúlio Vargas - foi um pulo: em 1934, quando 75\% da população do Brasil moravam no campo e $25 \%$ nas cidades, foi fixado o primeiro formato de vinculação: $10 \%$ dos impostos da União, 20\% dos Estados e 10\% dos Municípios para a MDE.

$\mathrm{Na}$ Constituição de 1946, em razão do aumento da demanda e da presença mais significativa dos municípios na oferta de escolas públicas, fixou-se uma segunda formatação: 10\% da União, 20\% dos Estados e $20 \%$ dos Municípios.

Contraditoriamente, a Constituição de 1967 - quando a população urbana acabara de ultrapassar a rural, provocando a explosão de matrículas, inclusive por se dobrar a duração da escolarização obrigatória - conservou aos percentuais de impostos para a MDE dos Estados e Municípios e retirou o dever constitucional da União. 
Dali até 1988, exatamente quando o governo federal arrecadou as maiores receitas da história, o aumento de encargos financeiros de todas as esferas administrativas foi viabilizado pelo corte na qualidade da educação pública e nos salários de seus profissionais. Sofremos as consequências até hoje.

A luta do Senador João Calmon ainda está na lembrança de muitos de nós; em 1983 emplacou sua Emenda, que fixou 13\% dos impostos da União, 25\% dos Estados e 25\% dos Municípios - o que resultava em aproximadamente $26 \%$ de ganho real para a educação.

Finalmente, a Constituição de 1988 dispôs que 18\% dos impostos da União, 25\% dos Estados e 25\% dos Municípios se aplicassem em MDE - o que foi reafirmado pelo art. 69 da Lei no 9.394, de 1996, Lei de Diretrizes e Bases da Educação Nacional - LDB, com três detalhes importantes: a exclusividade para a educação pública, a possibilidade de aumento de percentuais vinculados nas constituições estaduais e o dispositivo do repasse a cada dez dias dos recursos do órgão financeiro para o "órgão responsável pela educação". Resolução do Conselho Nacional de Educação elucidou que por "órgãos responsáveis pela educação" na União, nos estados, no Distrito Federal e nos municípios são os respectivos conselhos e secretarias de educação.

Quanto ao Salário Educação, a história é mais curta e mais simples, tendo evoluído na mesma lógica. Em 1964 foi criado o percentual de 1,4\% na folha de contribuição dos empregados de cada empresa privada, destinado aos ensino primário, então de quatro anos; em 1972, com a ampliação do ensino obrigatório para oito anos (então denominado de $1^{\circ} \mathrm{grau}$ ), a alíquota passou a ser de 2,5\%, que se mantém até hoje, embora sua destinação deva cobrir toda a educação básica, de dezessete a dezoito anos de duração.

\section{$O$ referencial ao PIB: Do ex-post ao ex-ante}

Tanto no caso dos impostos quanto no do Salário Educação, percebe-se que não basta qualquer aumento de arrecadação para se fazer face às despesas obrigatórias com a educação pública.

É verdade que, desde 1934, houve um aumento real de arrecadação. A grande questão é analisar se o aumento das demandas por investimentos na educação não é superior ao crescimento da receita, incluídos os recursos provenientes de "atualização" dos percentuais de MDE.

Ora, três variáveis históricas reais incrementaram a necessidade de novos e vultosos investimentos: o aumento de demanda por escolarização (maior população urbana); aumento de demanda de escolaridade (novos níveis de ensino), rumo à educação superior; aumento das exigências de qualidade do processo educativo escolar. Essas razões não somente fatos observáveis e registrados estatisticamente, como tendem a se acentuar nos próximos anos. As demandas quantitativas - mesmo com a queda da taxa de natalidade - são crescentes, inclusive numa faixa nova e pouco atendida, a da educação infantil. Já as demandas qualitativas se impõem pelo advento de novas tecnologias, pela necessidade de maior capacitação para o mundo do trabalho e pelo imperativo da volta à jornada curricular integral, como única forma provada de se superar o fosso das desigualdades sociais e os desafios da qualidade na aprendizagem.

Nesse contexto, a educação comparada, que analisa os diversos sistemas nacionais de educação, tem recorrido a um índice para avaliar o esforço de cada País em adotar políticas públicas na educação: trata-se do percentual do Produto Interno Bruto (PIB) que cada um aplica em sua rede de ensino, oferecido à população de forma gratuita, pelo menos na faixa da educação obrigatória.

A UNESCO tem-se esmerado em publicar as tabelas desses percentuais de aplicação, que são obtidos ex-post, ou seja, depois de verificado o total de gastos públicos em educação num determinado ano, divide-se esse número pelo valor do PIB obtido no mesmo ano. Embora não se deva desconsiderar os números absolutos (montante do PIB, total da receita pública, população estudantil, escolaridade da população - para citar alguns mais importantes), o número relativo, expresso pelo percentual de recursos públicos aplicados em educação em relação ao PIB, parece ser um dos indicadores mais importantes para se avaliar a política de educação de cada país no concerto das nações. 
É corrente a opinião de que o Brasil tem gasto (ou investido) em educação um percentual baixo em relação a seu PIB - números que vão de 3\% a 5\% nos últimos trinta anos, com subidas e descidas. Assim, foi "natural" se construir na opinião pública, principalmente entre os educadores, um consenso de que se deveria investir mais e mais - inclusive para se propiciar melhores salários para os profissionais. De 1990 a 200, tramitou no Congresso Nacional um projeto de lei fixando um PNE com previsão de despesas públicas em educação equivalentes a $10 \%$ do PIB. A Lei $n^{\circ} 10.172$, de 9 de janeiro de 2001, fixou 7\%, percentual que foi vetado pelo poder executivo com razões pífias, as quais escondiam argumentos tão poderosos quanto impublicáveis.

De 2003 em diante, existe uma sensação de que se aumentaram os gastos em relação ao PIB. Por duas razões, entre outras. A primeira foi o aumento real de arrecadação de impostos para a educação, acrescida pelo "dinheiro novo" da complementação da União ao Fundo de Manutenção e Desenvolvimento da Educação Básica e Valorização dos Profissionais da Educação - FUNDEB, que contribuíram para uma distribuição mais equânime e para um controle social mais visível, embora ineficaz na maioria dos entes federados. Focalizando somente o Imposto sobre Circulação de Mercadorias e Serviços (ICMS) - tributo de maior receita no Brasil, sua arrecadação em valores correntes parte de $R$ \$ 94,3 bilhões em 2001 e chega a $R$ \$ 270,7 bilhões em 2010 - 187\% de aumento diante de uma inflação pouco superior a 100\% no mesmo período. A segunda, muito propalada pela mídia oficial, foi a desativação da Desvinculação dos Recursos da União (DRU), que sequestrava mais de $20 \%$ dos impostos federais vinculados à MDE. A informação oficial dá conta de que se evoluiu de 3,9\% do PIB em 2003 para $5 \%$ em 2009.

Nada mais natural, portanto, que os educadores e outros cidadãos envolvidos na Conferência Nacional de Educação (Conae), realizada em abril de 2010, ainda lembrados do veto de Fernando Henrique Cardoso à meta de $7 \%$ do PIB e embalados pelo crescimento econômico e aumento dos investimentos em educação do Governo Lula, advogassem que se fixasse no PNE uma meta de aplicação de 10\% dos recursos públicos em relação ao PIB. Cumpre afirmar que a Emenda Constitucional n 59, de 2009, tinha acrescido ao art. 214 o dispositivo de obrigar o PNE a fixar a meta de aplicação de recursos relativos ao PIB.

\section{Sete ou dez por cento do PIB para a Educação ?}

Esse dilema, na verdade, não me parece ser o principal no financiamento da educação pública no Brasil, desde que se assegure um crescimento de despesas proporcional ao aumento quantitativo e qualitativo das demandas. O nó da questão é como transformar uma medida de avaliação (ex-post) em uma meta (ex-ante) e se garantir a efetividade desta meta numa República Federativa, com desproporcionalidade nas receitas e dispersão de responsabilidades.

O que significa transformar uma medida de avaliação tão ampla e global numa meta objetiva? Explicamonos. Uma coisa é ter no orçamento a vinculação de impostos e projetar a destinação de $25 \%$ ou $30 \%$ para a MDE, mês a mês, em cada estado e município - ou de 18\% na União. Os erros na previsão de receitas têm sido desprezíveis, tal o grau de cientificidade dos exercícios dos economistas. O mais difícil é a realização da despesa e sua qualidade como investimento - não como simples gasto, ou pior, como desperdício. Mudar o percentual do PIB, porém, do ex-post para o ex-ante, é quase um salto de trapezista. Primeiro, porque não se sabe qual o valor do PIB que o País alcançará até 31 de dezembro. Segundo, porque as receitas e despesas de impostos, de Salário Educação e de outros tributos que comporão o percentual do gasto em educação são sujeitos não somente a previsões, como a imprevistos. Terceiro, porque o percentual final da aplicação em educação pública será resultado da soma de diversos percentuais - da União, do conjunto de 26 Estados e do DF e do "pequeno" coletivo de 5.564 Municípios, que variam de um mil a onze milhões de habitantes.

Chegar a $7 \%$ em quatro anos, como afirmou a plataforma do Governo Dilma, era uma operação complexa, que supunha não somente marcos gradativos, a serem definidos no conjunto dos orçamentos públicos, conjugando 
compromissos da União, dos estados e dos municípios. Entretanto, ao fim do terceiro ano de seu governo (2013), não se chegou a 6\%. Pode-se ter também um aumento enganoso em 2014, em vista da estagnação do PIB, qualquer aumento de despesa em educação, que se dissolveria pelo crescimento do PIB, vai-se tornar mais visível. Corremos o "risco" de chegar a 6,5\% do PIB em 31 de dezembro de 2014 (ou seja, quase 10\% no percentual de investimento) com ganho real de investimento abaixo de 5\% - embora os prognósticos caminhem em sentido contrário, dada a redução de arrecadação de tributos da União já visível nos meados do ano.

Essa complexidade leva alguns estudiosos e políticos a invalidar o critério de melhorar a educação via percentual do PIB - preferindo as medidas de aumento real de arrecadação ou até mesmo de aumento dos percentuais. Contra essa última hipótese trabalham os dados históricos da evolução dos percentuais de MDE e do Salário Educação e a pressão dos outros setores da economia, que seriam necessariamente afetados - a não ser que ocorressem crescimentos do PIB acima de 5\% anuais, o que é muito improvável nos próximos dez anos.

Tenho uma posição média: se na administração pública temos um precedente de sucesso na política de ajuste fiscal, que é a composição do "superávit primário", como percentual do PIB oriundo da diferença entre receitas e despesas da União e dos entes federados, por que se arguiria impossibilidade ou impraticabilidade da mesma estratégia de gestão em relação à educação pública?

Ocorre que existe um componente político explosivo, tanto ou mais que no caso do "superávit primário", dentro do regime de cooperação dos entes federados no financiamento da educação: quem mais arrecada, a União, tem sido quem menos aplica em MDE desde que o Brasil é independente. E quem tem despendido cada vez mais é, exatamente, quem menos arrecada - o conjunto dos municípios. Como remontar essa equação? $\mathrm{Na}$ realidade, bastaria classificar uma série de gastos como "aplicações em educação" e poder-se-ia ganhar até 1\% do PIB: merenda escolar, bolsa-família, aposentadorias e pensões de educadores.

É preciso, ao afirmar as metas e estratégias, ter conceitos claros e definidos, para, então, distribuir a responsabilidade dos aumentos de encargos em cada conjunto federativo no alcance dos 7, 8, 9, até 10\% do PIB em educação. Traduzindo em reais, para 2014, em valores correntes, estima-se um PIB de $R \$ 5$ trilhões. O que significa que $7 \%$ seriam $R \$ 350$ bilhões; 10\%, R\$ 500 bilhões. Em 2013, os dados dos "dispêndios" em educação - neles incluída a maior parte de MDE - oscilam entre $R \$ 260$ e $R \$ 280$ bilhões. De onde brotariam os $R \$ 70$ ou $R \$ 90$ milhões que faltam?

No campo da ciência do financiamento, urge adotar-se um conjunto de conceitos e uma metodologia de interpretação idênticos para todas as contas que compõem a aplicação de recursos públicos em educação, inclusive traduzidos em artigos da LDB, semelhantes ao 70 e 71 que regulam o que é e o que não é despesa de MDE. Nessa hora, ensino é uma coisa; educação é outra, mais ampla. E são mesmo conceitos distintos. Mas não se pode alargar tanto que de ensino público se chegue a "educação societária permanente", nessa toada já teríamos até ultrapassado os $10 \%$ do PIB...

\section{As responsabilidades da União, dos estados, do DF e dos municípios para o aumento progressivo e sustentável do percentual do PIB aplicado em educação}

Grosso modo, pela legislação atual, cabe à União a educação superior e profissional; aos estados, o ensino médio em todas as suas modalidades e parte do ensino fundamental; aos municípios, a educação infantil e parte do fundamental; e ao Distrito Federal, toda a educação básica. Na realidade, quase todos os estados têm universidades e matrículas remanescentes na educação infantil, tanto quanto os municípios ainda sustentam cursos de ensino médio, até mesmo profissionais. A iniciativa privada, que já foi hegemônica na oferta de "ginásios e colégios" até 1960, atende hoje a 15\% das matrículas na educação como um todo, principalmente na educação superior (75\%), na profissional (50\%) e na infantil (40\%). Essa variação se reflete nas diferenças de gastos das diversas redes, de que decorrem variados percentuais em relação ao PIB.

Infelizmente, não conto com dados confiáveis, classificados pela ciência contábil, para descrever os percentuais de aplicação de recursos financeiros de cada um dos conjuntos em relação ao PIB. Em 2010, o PIB em valores 
nominais foi de $\mathrm{R} \$ 3,675$ bilhões. Diz-se que a União, naquele ano, não aportou recursos superiores a $1 \%$ do PIB ( $R \$ 36,75$ bilhões). Talvez seja uma questão de interpretação: trata-se do que ela aplicou diretamente em sua rede ou do que ela destinou a toda a educação escolar, incluindo as transferências? No segundo caso, só para a complementação do Fundeb e para as cotas estaduais e municipais do Salário Educação, foram mais de $R \$ 15$ bilhões. E como classificamos as transferências dos Fundos de Participação dos Estados e dos Municípios (FPE e FPM), dos quais 25\% são destinados à MDE? Nove estados da Federação têm no FPE receita maior que do próprio ICMS para a educação; e cerca de 2.000 Municípios "sobrevivem" do FPM - tal a penúria das receitas próprias e das transferências de ICMS e IPVA. Nessa linha de raciocínio, dos 5\% do PIB de 2010, 2\% teria derivado de arrecadação da União - a metade "transferida" para os entes federados. De qualquer maneira, uma análise fria dos números nos últimos dez anos revelará que o maior crescimento das despesas se deveu ao esforço fiscal da União.

Para se obter um diagnóstico preciso, de que sejam extraídas estratégias e ações para o PNE, para os PEE e para os PME impõe-se uma uniformização de critérios. Com este artigo, tento contribuir para clarear a questão das receitas e investimentos de cada uma das esferas do poder. Tanto na hipótese dos 7\% quanto na dos 10\% do PIB para a educação, ousaria propor como medida de aplicação dos recursos públicos arrecadados por cada conjunto, independente de onde foi investido, a seguinte proporção: dois quintos da União, outros dois dos estados e DF e um quinto dos municípios. Evidentemente, uma vez conhecidas essas proporções nos balanços de 2013 e 2014, esta proposta estaria sujeita à avaliação e a uma programação de ajuste gradual, sempre em direção à qualidade da educação pública, porque no mundo real e nas finanças, não se fazem saltos.

Cumpre agora indicar as possíveis fontes dos novos investimentos em educação escolar pública e a enumeração das estratégias gerais, entre as quais enfatizo o que chamo de "compromissos federais".

\section{Fontes para a expansão dos investimentos públicos em educação}

No âmbito da União, pode-se, além de se majorar levemente o percentual de impostos para a MDE (de 18\% para 20\%) e de elevar a alíquota do Salário Educação para 3,5\%, pensar numa destinação para a educação em geral das Contribuições Sociais (Cofins, CSLL, PIS-PASEP, etc), gradativa até 10\% em cinco anos. Tais medidas, a médio prazo, poderiam dobrar a capacidade de investimento da União na educação superior e básica, especialmente para aumentar a complementação do Fundeb e ampliar a rede de universidades e institutos federais. Caberia também à União potencializar a arrecadação do ITR (hoje absurdamente baixa, de cerca de $\mathrm{R} \$ 1,00$ por hectare) e direcionar as receitas dos royalties do petróleo para o Fundeb, em especial para a remuneração digna dos profissionais da educação.

No âmbito dos estados, do Distrito Federal e dos municípios, a proposta seria a de generalizar a vinculação de $30 \%$ dos impostos e transferências para a MDE - já praticada por oito estados e muitos municípios. Desses $30 \%, 25 \%$ ficariam adstritos à educação básica pública (continuando a redistribuição de 20\% para o Fundeb) e $5 \%$ poderiam ser destinados a qualquer nível, etapa ou modalidade do ensino, a critério dos planos estaduais e municipais de educação. Para aumentar a arrecadação de ICMS, seria revista a imunidade constitucional (oriunda da Lei Kandir) dos produtos exportados, o que tem reduzido drasticamente a capacidade de receita de muitos estados e seus municípios. Basta lembrar o caso do Pará, talvez o território mais rico do País: exportados o minério, a madeira, os grãos e a carne sem pagamento de impostos, a União precisa lhe transferir mais de $R \$$ 2 bilhões a título de complementação do Fundeb...

Nos municípios seriam potenciados os impostos que derivam da capacidade contributiva dos seus cidadãos e empresas: ITR, IPTU, ISS e IRRF dos servidores públicos. Numa democracia, o princípio que funda a presença do estado nas políticas sociais é o dos direitos sociais (educação, saúde, transporte, previdência, etc), garantidos pela canalização de recursos financeiros baseados na capacidade contributiva de pessoas físicas

e jurídicas. A humanidade evoluiu das práticas predatórias e individualistas para o princípio universalmente 
aceito de convivência: "a cada um segundo suas necessidades, cobrando de cada um segundo sua capacidade". É uma irresponsabilidade fiscal convivermos com fortunas de pessoas e empresas que não são taxadas proporcionalmente à sua capacidade - não só pagam um IR desprezível, não só não são cobrados pelo Imposto sobre Grandes Fortunas, como não são alcançados pelos tributos patrimoniais, como o ITR e IPTU. Na vizinhança do MEC, no Distrito Federal, mansões pagam IPTU em valores subestimados e os professores têm parte de seus salários providos pelo "Fundo Constitucional" do DF, oriundo de tributos que gravam os estados e municípios de todo o país. O que dizer da prática anti-cidadã de cartórios que sub-valorizam casas e terrenos para reduzir o valor do ITBI e a alíquota de 4\% do Imposto sobre Heranças (ITBDCM), que nos países avançados é de mais de $40 \%$ e representa a contribuição dos que acumularam riquezas para as novas gerações?

Concluindo esta seção do artigo: só chegaremos a 10\% do PIB com mais arrecadação. Ou, ironicamente, com a diminuição do ritmo de crescimento e com maior inflação. Imagino que ninguém aposta nessas tragédias...

\section{Breve análise da Meta 20 e das estratégias de financiamento no PNE}

É fundamental partirmos do texto da Meta e das doze estratégias:

Meta 20. Ampliar o investimento público em educação pública de forma a atingir, no mínimo, o patamar de 7\% do PIB do País no quinto ano de vigência desta Lei e, no mínimo, o equivalente a $10 \%$ do PIB no final do decênio.

Estratégias

20.1) garantir fontes de financiamento permanentes e sustentáveis para todos os níveis, etapas e modalidades da educação básica, observando-se as políticas de colaboração entre os entes federados, em especial as decorrentes do art. 60 do Ato das Disposições Constitucionais Transitórias e do $\$ 1^{\circ}$ do art. 75 da Lei $n^{\circ} 9.394$, de 20 de dezembro de 1996, que tratam da capacidade de atendimento e do esforço fiscal de cada ente federado, com vistas a atender suas demandas educacionais à luz do padrão de qualidade nacional;

20.2) aperfeiçoar e ampliar os mecanismos de acompanhamento da arrecadação da contribuição do Salário Educação;

20.3) destinar à manutenção e desenvolvimento do ensino, em acréscimo aos recursos vinculados nos termos do art. 212 da Constituição Federal, na forma de lei específica, a parcela da participação no resultado ou da compensação financeira pela exploração de petróleo e gás natura e outros recursos, com a finalidade do cumprimento da meta prevista no inciso VI do caput do art. 214 da Constituição Federal;

20.4) fortalecer os mecanismos e os instrumentos que assegurem, nos termos do parágrafo único do art. 48 da Lei Complementar $n^{\circ}$ 101, de 4 de maio de 2000, a transparência e o controle social na utilização dos recursos públicos aplicados em educação, especialmente a realização de audiências públicas, a criação de portrais eletrônicos de transparência e a capacitação de membros dos conselhos de acompanhamento e controle social do Fundeb, com a colaboração entre o Ministério da Educação, as Secretarias de Educação dos Estados e dos Municípios e os Tribunais de Contas da União, dos Estados e dos Municípios;

20.5) desenvolver, por meio do Instituto Nacional de Estudos e Pesquisas Educacionais Anísio Teixeira INEP, estudos e acompanhamento regular dos investimentos e custos por aluno da educação básica e superior pública, em todas as suas etapas e modalidades;

20.6) no prazo de dois anos da vigência deste PNE, será implantado o Custo-Aluno-Qualidade inicial - CAQi, referenciado no conjunto de padrões mínimos estabelecidos na legislação educacional e cujo financiamento será calculado com base nos respectivos insumos indispensáveis ao processo de ensino-aprendizagem e será progressivamente reajustado até a implementação plena do Custo-Aluno-Qualidade - CAQ;

20.7) implementar o Custo-Aluno-Qualidade - CAQ, como parâmetro para o financiamento da educação de todas as etapas e modalidades da educação básica, a partir do cálculo e do acompanhamento regular dos indicadores de gastos educacionais com investimentos em qualificação e remuneração do pessoal docente e dos 
demais profissionais da educação pública, em aquisição, manutenção, construção e conservação de instalações e equipamentos necessários ao ensino e em aquisição de material didático-escolar, alimentação e transporte escolar;

20.8) o CAQ será definido no prazo de três anos e será continuamente ajustado, com base em metodologia formulada pelo Ministério da Educação - MEC, e acompanhado pelo Fórum Nacional de Educação, pelo Conselho Nacional de Educação - CNE e pelas Comissões de Educação da Câmara dos Deputados e de Educação, Cultura e Esportes do Senado Federal;

20.9) regulamentar o parágrafo único do art. 23 da Constituição Federal, no prazo de dois anos, por lei complementar, de forma a estabelecer as normas de cooperação entre a União, os Estados, o Distrito Federal e os Municípios, em matéria educacional, e a articulação do sistema nacional de educação em regime de colaboração, com equilíbrio na repartição das responsabilidades e dos recursos e efetivo cumprimento das funções redistributiva e supletiva da União no combate às desigualdades educacionais regionais, com especial atenção às regiões Norte e Nordeste;

20.10) caberá à União, na forma da lei, a complementação de recursos financeiros a todos os Estados, ao Distrito Federal e aos Munic ípios que não conseguirem atingir o valor do CAQi e, posteriormente, do CAQ;

20.11) aprovar, no prazo de um ano, Lei de Responsabilidade Educacional, assegurando padrão de qualidade na educação básica, em cada sistema e rede de ensino, aferida pelo processo de metas de qualidade aferidas por institutos oficiais de avaliações educacionais;

20.12) de finir critérios para distribuição dos recursos adicionais dirigidos ao longo do decênio, que considerem a equalização das oportunidades educacionais, a vulnerabilidade socioeconômica e o compromisso técnico e de gestão do sistema de ensino, a serem pactuados na instância prevista no $§ 5^{\circ}$ do art. $7^{\circ}$ desta Lei.

Celebremos, em primeiro lugar, o texto da Meta 20. Além de se preservar o sentido original do art. 214, do objetivo de se pactuar o percentual de recursos públicos investidos em educação pública, são fixadas duas metas ao longo do decênio: $7 \%$ e 10\% no quinto e décimo ano, respectivamente. Embora não tenha ficado claro, nas estratégias, de que percentual se parte - poderia ser o de 5,6\% em 2013? - é importante ter a meta intermediária mais próxima num valor menos ousado, inclusive para dar tempo a mudanças legislativas e de gestão necessárias para se atingir as metas.

Uma das mudanças legislativas diz respeito à uniformização dos percentuais de impostos vinculados à MDE - se possível na perspectiva proposta neste artigo, de 30\% para a educação, sendo $25 \%$ para a educação básica e $20 \%$ para o Fundeb.

Mudança urgente que afeta a capacidade de investimento da União em educação é uma proposta de emenda à Constituição para desvincular das principais contribuições sociais, gradativamente, até 10\% de suas receitas para a MDE, se possível destinados ao Fundeb e à viabilização do Piso Salarial Nacional dos Profissionais da Educação, segundo o art. 206 da Constituição.

Importante também será a definição de uma política de financiamento para as Universidades Federais e os Institutos Federais de Educação, Ciência e Tecnologia. Podemos, inclusive, resgatar a ideia - válida também para as instituições estaduais de educação superior - de se criar uma contribuição social semelhante à do Salário Educação, que não gravasse empresas, mas os concluintes de cursos superiores gratuitos, em valores discretos mas contínuos, proporcionais a suas rendas anuais aferidas pela Receita Federal. Há dez anos, calculei que um adicional ao IR, de 3\% sobre a renda bruta, seria suficiente para duplicar as receitas que hoje sustentam as universidades federais e estaduais. Com o extraordinário incremento de concluintes de cursos superiores gratuitos no último decênio, criar-se-ia um círculo virtuoso capaz de reverter nossa situação de inferioridade em termos de atendimento na educação superior no conjunto de países da América Latina.

A introdução dos conceitos do CAQ e do CAQi exige, a curto prazo, a reformulação de dispositivos do Fundeb que atualmente regulam o valor mínimo anual por aluno e, consequentemente, o quantitativo necessário para a 
complementação da União. Na verdade, o INEP e outras instituições do MEC terão a responsabilidade de fixar valores - inclusive variados entre escolas de jornada integral e turno parcial - que, devidamente aplicados aos orçamentos da União, dos estados, do DF e dos municípios, revolucionarão o financiamento. Parece-me urgente que se transforme a atual Secretaria de Articulação dos Sistemas de Ensino (SASE) numa Secretaria de Planejamento Articulado do Sistema Nacional de Educação, a ser dotada de técnicos de alto nível com formação e experiência multidisciplinar, para dar conta da complexidade da nova proposta a ser implementada a partir de 2016 (ou 2017?).

A maior dificuldade de implementação da Meta 20, entretanto, tem a ver com dois procedimentos urgentes, contra os quais pesam consideráveis obstáculos.

O primeiro é o da elaboração ou adequação dos Planos Estaduais e Municipais de Educação, para o que a lei deu prazo até dia 25 de junho de 2015, conforme seu artigo $8^{\circ}$. Os PEE e PME abrangem $90 \%$ dos 50 milhões de atendidos na educação básica e superior; e cerca de 90\% dos que se deve atender, principalmente na educação infantil, na EJA e na educação profissional. Ora, só chegaremos a 7\% do PIB do país em 2019 se planejarmos investir, em cada estado, no DF e em cada município, 7\% ou mais do PIB de cada ente federado. Exemplificando: o Acre já investe mais de 10\% de seu PIB em educação, somando os gastos ali feitos pela União, governo estadual e governos municipais. Ou seja, ele já chegou a 2023. Mas tem pouco peso no resultado geral do País, por sua pequena população. Mas São Paulo investe menos de 5\% de seu PIB. O mesmo acontece com o Distrito Federal. Ora, na conta da composição do PIB-Brasil, São Paulo + DF representam mais de 20\%, enquanto o Acre não chega a 0,5\%. Em outras palavras - os 7\% e 10\% do PIB não são um ato de voluntarismo do Governo Federal, mas um esforço do país como um todo. Não desanimemos...

O segundo procedimento tem a ver com um conflito de legislação que está impedindo o avanço do atendimento à demanda por educação e a melhoria dos salários dos profissionais da educação. De um lado, o Fundeb exige que pelo menos $60 \%$ de sua receita, em cada estado e município, sejam destinados ao pagamento dos professores em exercício. De outro, a Lei de Responsabilidade Fiscal impede que se ultrapasse a 49\% e 54\%, respectivamente, em gastos com pessoal. Ora, educação é uma política pública que responde a direitos constitucionais, inalienáveis e se caracteriza pela massiva concentração de gastos com pessoal - professores, gestores e funcionários das escolas, que consomem entre $80 \%$ e $90 \%$ de suas receitas. A solução tem sido não abrir mais vagas, não dar aumentos de salários, não contratar mais professores - o que redunda em precarização, terceirização e privatização. Está na hora de se rasgar a fantasia. O Ministério da Fazenda, o Ministério da Educação, o Congresso Nacional, o Tribunal de Contas da União e o Poder Judiciário precisam se entender com urgência. Senão, o incrível vai acontecer: o Ministério da Educação, as Secretarias de Educação com as burras repletas de reais, tendo que devolver os recursos ou gastá-los nos prédios das escolas, em pisos de mármores e vasos de ouro.

\section{Referências}

BRASIL. Constituição Federal de 1988. Disponível em http://www.planalto.gov.br/ccivil_03/constituicao/ constituicaocompilado.htm

. Lei de Diretrizes e Bases da Educação Nacional, Lei Federal 9.394/96. Disponível em http://www. planalto.gov.br/ccivil_03/leis/19394.htm.

Lei de Responsabilidade Fiscal, Lei Complementar 101/2000. Disponível em http://www.planalto.gov. br/ccivil_03/leis/lcp/lcp101.htm.

Lei do Plano Nacional de Educação, Lei Federal 13.0005/14. Disponível em http://www.planalto.gov. br/ccivil_03/_Ato2011-2014/2014/Lei/L13005.htm

Recebido em Setembro de 2014 - Aprovado em Novembro de 2014 